\title{
Jean-Pierre Bertrand, Se taire et le dire: la poétique de la parole chez Laforgue
}

\section{Sandra Garbarino}

\section{Q OpenEdition}

1 Journals

\section{Edizione digitale}

URL: https://journals.openedition.org/studifrancesi/41041

DOI: 10.4000/studifrancesi.41041

ISSN: 2421-5856

\section{Editore}

Rosenberg \& Sellier

\section{Edizione cartacea}

Data di pubblicazione: 1 juillet 2004

Paginazione: 215

ISSN: 0039-2944

\section{Notizia bibliografica digitale}

Sandra Garbarino, «Jean-Pierre Bertrand, Se taire et le dire: la poétique de la parole chez Laforgue», Studi Francesi [Online], 142 (XLVIII | I) | 2004, online dal 30 novembre 2015, consultato il 09 septembre 2021. URL: http://journals.openedition.org/studifrancesi/41041; DOI: https://doi.org/10.4000/studifrancesi. 41041

Questo documento è stato generato automaticamente il 9 septembre 2021.

\section{(c) 9 (i) $\Theta$}

Studi Francesi è distribuita con Licenza Creative Commons Attribuzione - Non commerciale - Non opere derivate 4.0 Internazionale. 


\title{
Jean-Pierre Bertrand, Se taire et le dire: la poétique de la parole chez Laforgue
}

\author{
Sandra Garbarino
}

\section{NOTIZIA}

JEAN-PIERRE BERTRAND, Se taire et le dire: la poétique de la parole chez Laforgue, in A.A.V.V., Spectacles de la parole, a cura di Hélène Millot e Corinne Saminadayar-Perrin, Édition des Cahiers Intempestifs, 2003, («Lieux littéraires»), pp. 243-262

1 Scopo di questo articolo lo studio della poetica di Jules Laforgue, condotto attraverso un rapida panoramica sulle sue Complaintes e un'osservazione più approfondita di una complainte in particolare, la «Complainte des formalités nuptiales». Per ciò che concerne l'opera in generale, l'A. sottolinea come la scelta di tale mezzo espressivo sia effettuata più per «défaut» che per «défi», ovvero per mancanza di un'altra forma poetica in grado di contenere al contempo «du roman, du théâtre, de la philosophie». Questa una serie di 50 quadri successivi nei quali lo scrittore sperimenta l'atto della parola, mettendo in scena personaggi e situazioni di vario genere, alternano lacrime e sorrisi, melodrammi e pastiches, canzoni e parodie. Ed è proprio per la loro varietà che le Complaintes di Laforgue vengono definite da J.-P. Bertrand un «recueil music-hall». Nonostante questa varietà, le scene rappresentate all'interno delle complaintes sono raggruppabili in 4 categorie: quelle che si svolgono all'aperto, quelle che si svolgono in uno spazio chiuso, quelle in cui non viene menzionato alcun riferimento spaziale e quelle che hanno per scena un luogo ideale, utopico.

2 Per quanto riguarda la «Complainte des formalités nuptiales», l'A. sviluppa un'analisi conversazionale il cui obiettivo dichiarato è quello di studiare lo stato della parola attraverso lo studio degli scambi di battute tra i due personaggi principali del poema in questione. Risultato di questa osservazione è la constatazione che, per Laforgue, il 
parlare si sostituisce al fare quando si tratta d'amore e di sentimenti. Dal punto di vista filosofico, questa complainte ironizza sulle convenzioni borghesi e mette in luce il dramma delle formalità nascoste dietro ogni situazione. 